\title{
The modelling of soil plasticity
}

\author{
Cheng Y $\mathrm{P}^{1}$, Bolton $\mathrm{M} \mathrm{D}^{2}$, Nakata $\mathrm{Y}^{3}$
}

\section{Introduction}

Crushable agglomerates can be simulated in the distinct element method (DEM) by bonding elementary spheres in 'crystallographic' arrays. The behaviour of an element comprising these numerically-generated soil grains resembles that of a crushable anisotropic sand, in terms of irrecoverable compression, yielding and plastic hardening behaviour. Stress path tests are simulated to capture the response of the simulated soil to various combinations of deviatoric and spherical stress changes, $\delta \mathrm{q}$ and $\delta \mathrm{p}$, in both loading and unloading. The plastic deformation is comparable with certain features of the Cambridge soil plasticity models, although the definition of a single yield surface separating elastic from plastic behaviour is arbitrary, exactly as it is with actual triaxial tests on real soils. Normality of the plastic strain increment vector to conventionally defined yield surfaces is not observed. It is shown that grain breakage is a crucial component of plastic soil behaviour.

Yield surfaces obtained from numerical stress-path tests are best quantified by the percentage of bond-breaking (pbb) contours. These surfaces are compared with contours of yield defined alternatively from inspecting stress-strain curves. An "elastic wall" in voids ratio $\log$ mean effective stress (e, ln $p^{\prime}$ ) space is found, but the normality rule is not followed at yield. Similarity is observed in the shapes of yield surfaces at different degrees of strain-hardening, both in the e-ln $\mathrm{p}^{\prime}$ space and the q-p' space. Their shape resembles the Modified Cam Clay model more than the Original. Lastly, a reduction of internal coefficient of friction, represented by the Cam Clay parameter M, is observed when stress-level is increased; this also resembles real soils.

\footnotetext{
${ }^{1}$ Student, Geotechnical Research Office, Department of Engineering, Cambridge University, Trumpington Street, Cambridge CB2 1PZ, U.K.; phone: +44-1223766686; Fax: +44-1223-339713; ypc21@eng.cam.ac.uk

${ }^{2}$ Professor, Department of Engineering, Cambridge University; mdb@eng.cam.ac.uk

${ }^{3}$ Associate Professor, Department of Civil Engineering, Yamaguchi University, Tokiwadai 2-16-1, Ube 755-8611; nakata@yamaguchi-u.ac.jp
} 

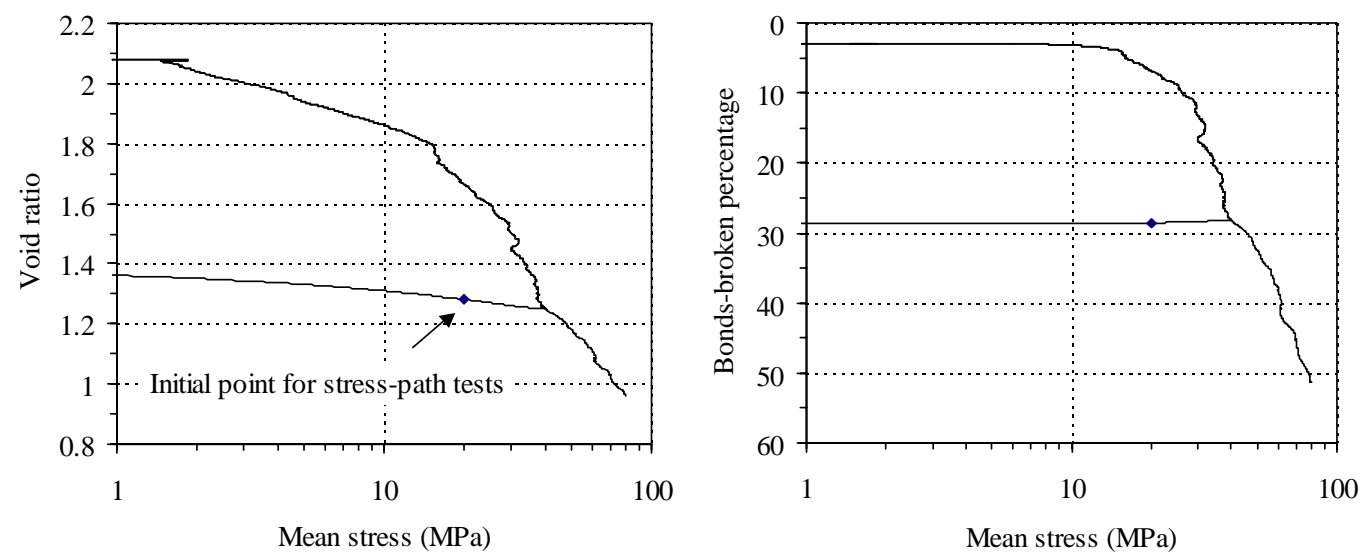

Figure 1 Isotropic compression curve : (a) e-lnp' (b) bond-broken\%-ln p'

\section{Crushing}

The importance of soil crushing to the behaviour of soil has been becoming obvious since Bolton (1986). Nakata et al (2001) performed soil tests comparing singleparticle crushing strengths with the experimental behaviour of a soil aggregate. Robertson \& Bolton (2001) modelled crushable agglomerates with DEM simulations. Simulations and experiments have been compared by Nakata, Cheng \& Bolton (2002). They showed that, when a simulated soil aggregate is made from agglomerates whose strengths vary according to the Weibull distribution, the results of isotropic compression and shearing simulations compare very well to real soil tests. Figure 1 shows the result of an isotropic compression test when each pair of faces of an elementary cube approach each other with a speed of $1 \mathrm{~m} / \mathrm{s}$. Figure 1(a) plots the voids ratio, conventionally defined as the volume of voids divided by the volume of solids, against the mean stress, which is experienced by the soil mass in contact with all the walls. Figure 1(b) plots the percentage of bonds broken against the corresponding mean stress. The bonds are simple-contact bonds that bond the spheres to form the agglomerates.

It is seen that significant bond breakage happens only after about $15 \mathrm{MPa}$. The volume of the soil mass, however, starts decreasing well before $2 \mathrm{MPa}$. Pure rearrangement of 'grains' contributes to the volume reduction before bond breakage, after which broken fragments can repack more efficiently in voids and encourage more rearrangement and enhanced compression. Three obvious stages of monotonic compression can be distinguished in e-ln $\mathrm{p}^{\prime}$ space in this simulation. The final stage of compression is a straight line whose slope is the isotropic hardening parameter, $\lambda$. Unloading is then allowed at 40MPa. A small amount of breakage is observed in the initial stage of unloading. No further breakage is seen from the figure when more stress is released; the mean stress is reduced by an "over-consolidation ratio" of 2 . Stress path tests with various deviatoric / mean stress changes from the starting point of $\mathrm{p}^{\prime}=20 \mathrm{MPa}$ were then simulated and analysed as shown in Figure 1. 

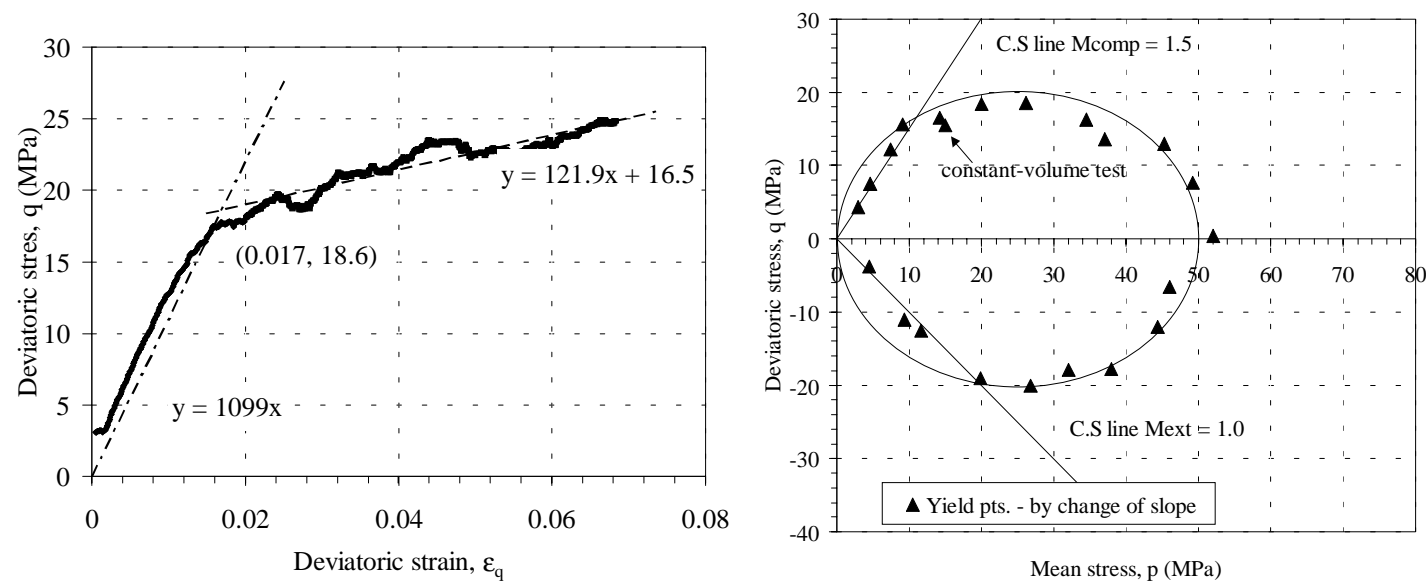

Figure 2 Yield points determined by curve fitting

\section{Plastic deformation}

Figure 2 shows the yield points of all stress path tests determined by curve fitting. Each yield point is obtained as the intersection of two best-fit lines when the corresponding deviatoric stress-strain curve is plotted (Figure 2a). The triangles shown in Figure $2 \mathrm{~b}$ are all the yield points; they are then compared to a modified Cam-clay yield surface. The two critical state lines with $\mathrm{M}_{\text {comp }}=1.5$ and $\mathrm{M}_{\mathrm{ext}}=1.0$, which both conform to Mohr-Coulomb friction angles $\phi^{\prime}=37^{\circ}$, are also plotted in the figure.

The compression of the soil (Figure 1) can be reasonably fitted first by using gradient $\kappa=0.04$, and then $\lambda=0.4$. Figure $3 a$ shows also the stress-path in the e-ln $\mathrm{p}^{\prime}$ space. The pbb contours are marked as circles along each stress path. An additional $\kappa$-line $\left(\mathrm{p}_{\mathrm{c}}=\right.$ $50 \mathrm{MPa}$ ) is drawn on the figure. It is seen that the concept of an elastic wall bounded by a yield surface works reasonably well, although variation is observed near the intersection of the $\kappa$-line and the $\lambda$-line.
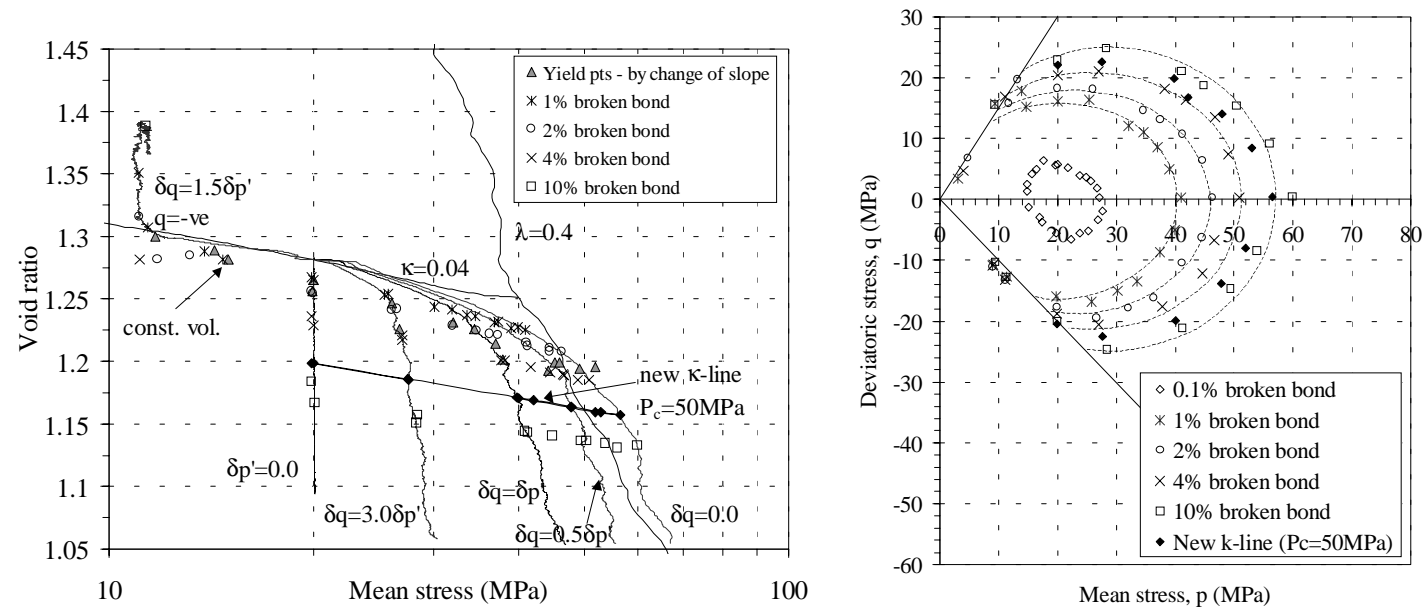

Figure 3 Projection of elastic walls of e-lnp' space onto the q-p' space 


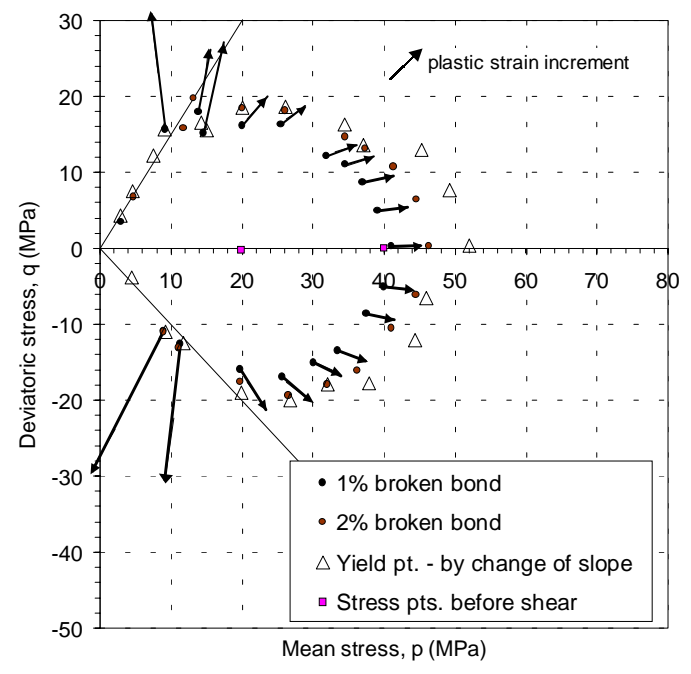

Figure 4 Plastic strain increments: normality is not followed

When points along the elastic wall $\left(\mathrm{p}_{\mathrm{c}}=50 \mathrm{MPa}\right)$ are plotted in the $\mathrm{q}-\mathrm{p}$ ' plot, as the squares in Figure $3 b$, the shape of the yield surface resembles the pbb contours. The pbb contours seem to be a more meaningful representation of the yield surface in the numerical simulation than the Modified Cam Clay model (Figure 2b). The direction of plastic deformation is calculated by assuming elastic volumetric strain produced when $\kappa=0.04$, and the elastic deviatoric strain is negligible. The results are plotted in Figure 4. Both of them show that the plastic flow follows non-associated flow rule rather than the normality rule. Of course, we also know that the $\kappa$-lines are not truly elastic, but rather lines of constant granulometry (no fragment creation).

The stress-dilatancy function of the numerical tests is calculated. Figure 5a shows that when this function

$$
\frac{q}{p}+\frac{d \varepsilon_{v}^{p}}{d \varepsilon_{q}^{p}}
$$

is plotted against the stress path direction, the DEM simulations give results which are different from the original Cam Clay Model. This function in the original Cam Clay model should equate to a constant M (Roscoe, Schofield. \& Thurairajah, 1963). The figure shows that this varies instead. The formulation of the Modified Cam Clay model, however, includes plastic dilatancy rate (Roscoe, \& Burland, 1968)

$$
\frac{q}{p}+\frac{d \varepsilon_{v}^{p}}{d \varepsilon_{q}^{p}}=\sqrt{M^{2}+\left(\frac{d \varepsilon_{v}^{p}}{d \varepsilon_{q}^{p}}\right)^{2}},
$$




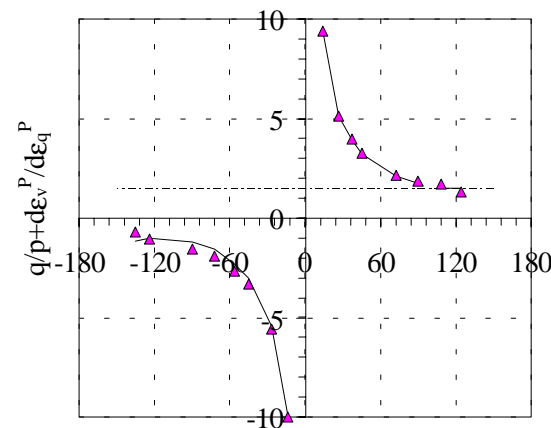

Stress-path direction (degree)

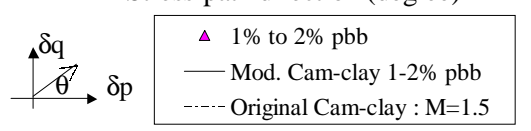

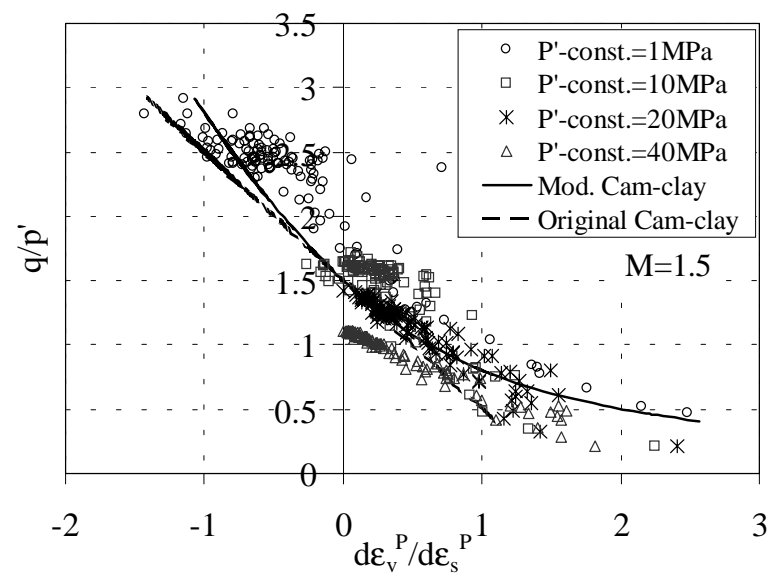

3

Figure 5 Stress-dilatancy of numerical tests

which then gives a somewhat better fit. This is especially important for the lowgradient stress-paths when the compression effect is more important than the frictional effect.

The tests shown in Figure $5 \mathrm{~b}$ are all constant- $\mathrm{p}^{\prime}$ tests on normally consolidated "numerical soil" from various points along the virgin $\lambda$-line. The DEM simulations demonstrate realistic stress-level dependence on internal friction, since the critical state parameter, M, decreases with increasing stress. Both Cam Clay models fail to capture this effect which is a reliable feature of all soil tests.

\section{Reference}

Bolton, M. D. (1986). "The strength and dilatancy of sands." Geotechnique 36, No.1, 65-78.

Nakata, Y., Kato,Y. \& Hyodo M., Hyde, A. L. \& Murata, H. (2001). "Onedimensional compression behaviour of uniformly graded sand related to single particle crushing strength." Soils Found 41, No. 2, 39-51.

Nakata, Y., Cheng, Y. P. \& Bolton, M. D. (2002). "DEM simulations of crushable soil." (2002). Geotechnique, in press.

Robertson, D. \& Bolton, M. D. (2001). "DEM simulations of crushable grains and soils." Powders and Grains 2001, Kishino (ed.), 623-626.

Roscoe, K. H., Schofield, A. N. \& Thurairajah A. (1963). "Yielding of clays in states wetter than critical." Geotechnique 13, 211-240

Roscoe, K. H. \& Burland, J. B. (1968). "On the generalized stress-strain behaviour of 'wet' clay." Engineering Plasticity, Heyman J \& Leckie FA (ed.) Cambridge University Press, 535-609. 